05

\title{
Электропроводящие и оптические свойства сополимера поливинилхлорид-полиацетилен
}

\author{
() С.И. Расмагин, В.И. Крыштоб \\ Институт общей фризики им. А.М. Прохорова РАН, \\ 119991 Москва, Россия \\ e-mail: rasmas123@yandex.ru
}

Поступило в Редакцию 13 июня 2019г.

В окончательной редакции 13 июня 2019г.

Принято к публикации 24 декабря 2019 г.

Исследована температурная зависимость проводимости пленок термообработанного поливинилхлорида, содержащего в цепи своих макромолекул сопряженные двойные углеродуглеродные связи и представляющего собой сополимеры поливинилхлорид-полиацетилен. В образцах с превышением „пороговой“ концентрации сопряженных двойных связей углерода и связанных с ними носителей заряда (л-электроны) обнаружены переключения проводимости на 10 порядков величины по мере увеличения температуры. Обнаружена неустойчивость состояния с полупроводящей проводимостью в интервале температур, ширина которого зависит от концентрации сопряженных двойных углерод-углеродных связей и связанных с ними носителей заряда. Качественно увеличение концентрации сопряженных двойных углерод-углеродных связей контролировалось посредством фиксации фотолюминесцентных спектров и инфракрасных спектров поглощения.

Ключевые слова: поливинилхлорид, фотолюминесцентные спектры, инфракрасные спектры, температурная зависимость удельного сопротивления.

DOI: 10.21883/JTF.2020.06.49281.238-19

\section{Введение}

Наибольшее практическое применение в реальной жизни имеют органические высокомолекулярные полимеры. Например, при легировании иодом $\mathrm{I}_{2}$ и литием $\mathrm{Li}$ полиацетилена получили полупроводниковые полимеры соответственно с $n$ - и $p$-типом проводимости. К сожалению, полиацетилен является малотехнологичным полупроводниковым полимером, поэтому необходимо использовать другие полимеры, например поливинилхлорид (ПВХ). При термообработке ПВХ при высоких температурах происходит создание фрагментов сопряженных двойных углерод-углеродных связей или другими словами в ПВХ образуются фрагменты полиацетилена (ПАЦ). При этом в созданном сополимере ПВХ-ПАЦ сохраняется высокоэластичность, пластичность и другие технологические свойства. Для получения информации об оптических и электрофизических свойствах сополимера ПВХ-ПАЦ используются различные методы, например метод определения удельного сопротивления от температуры измерения образцов. Температурная зависимость удельного сопротивления (проводимости) является информативным методом выявления физических механизмов переноса носителей заряда в полимерных, полупроводниковых и композитных материалах. Ионный механизм Френкеля-Шоттки [1,2] и прыжковые механизмы проводимости в модели Мотта описываются феноменологической формулой для удельного сопротивления

$$
\rho=\rho_{0} \cdot \exp \left(-(W / T)^{\gamma}\right)
$$

где константы $\rho_{0}$ и $W$ определяются из эксперимента, а коэффициент $\gamma$ определяет наклон прямой в координатах $\ln (\rho)\langle=\rangle 1000 / T$. Если в исследуемом образце реализуется прыжковый механизм Мотта [2], то $\gamma=1 / 4$, для механизма Френкеля-Шоттки - $\gamma=1$. В металлоподобных материалах с частично заполненной зоной изменение проводимости от температуры обнаруживает положительный температурный коэффициент сопротивления (ТКС). В полупроводниках ТКС отрицателен, поскольку увеличение температуры приводит к появлению частиц носителей заряда с большими энергиями, которые могут переходить в зону проводимости. Это приводит к увеличению подвижности зарядов и соответственно увеличению частоты и дальности прыжков. Для широкозонных полимерных материалов со свойствами, близкими к изоляторам, предлагается ионный тип проводимости. Повышение температуры приводит к высвобождению зарядов (в том числе и ионов) из дефектных узлов, ловушек и примесей. Характерная зависимость сопротивления термопластичного полимера в координатах $\log (\sigma)\langle=\rangle 1000 / T$ имеет кусочно-линейный вид [1]. Участки, соответствующие стеклообразному состоянию полимера, хорошо аппроксимируются отрезками прямых, а вязко-текучее состояние скорее напоминает криволинейный отрезок.

\section{Экспериментальная часть}

В качестве исходного ПВХ использовали гранулы размером 150-200 $\mu \mathrm{m}$ суспензионного ПВХ мар- 


\section{Semiconductor \\ Insulator

\begin{tabular}{|c|c|}
\hline & \\
\hline \multirow[b]{2}{*}{$\mathrm{CH}=\mathrm{CH}$} & $\mathrm{Cl}$ \\
\hline & $\mathrm{CH}_{2}-\mathrm{CH}-\mathrm{CH}_{2}-\mathrm{CH}-\mathrm{CH}_{2}$ \\
\hline
\end{tabular}

Рис. 1. Структура макромолекул сополимера ПВХ-ПАЦ (в реальных образцах макромолекулы ориентированы хаотически).

ки С-7058М. Согласно техническим характеристикам, данная марка ПВХ содержит не более 16 различных примесей (олефиновые группы, третичный углерод, кислород и др.). Эти примеси содержатся в незначительных количествах (менее $0.1 \%$ ), как правило, электрически нейтральны и поэтому дают малый вклад в проводимость, которым можно пренебречь. Из исходного ПВХ в растворе тетрагидрофурана была получена пленка без термообработки [3]. Из исходного ПВХ методом термолиза в растворе ацетофенона были приготовлены пленки при разных временах процесса термообработки $[3,4]$. В результате получили четыре образца: первый образец 1 (исходный) термообработка в течение $0 \mathrm{~min}$, второй $2-240 \mathrm{~min}$, третий $3-320 \mathrm{~min}$ и четвертый $4-420 \mathrm{~min}$. Полученные пленки 2-4 являются сополимерами ПВХ-ПАЦ. Провели исследования температурной зависимости сопротивления образцов сополимера ПВХ-ПАЦ для различных концентраций сопряженных двойных углерод-углеродных связей (СДС). В таких сополимерах наблюдаются обратимые, спонтанные и стимулированные внешними воздействиями переключения проводимости из состояния низкой проводимости (СНП) в состояние высокой проводимости (СВП) с перепадом на 10 порядков величины $[4,5]$. $\mathrm{B}$ настоящей работе с целью выявления физических механизмов аномальных переключений выполнены исследования температурной зависимости в диапазоне $t=15-85^{\circ} \mathrm{C}$ электропроводимости для серии образцов сополимеров ПВХ-ПАЦ с различным содержанием фрагментов сопряженных двойных связей углерода. На рис. 1 представлена структура молекулы сополимера ПВХ-ПАЦ.

Для количественного подтверждения различной степени нагрева исходного ПВХ и корреляции ее со временем термообработки в растворе дополнительно проводилось исследование фотолюминесцентных свойств полученных пленок [6]. В данной работе исследовались температурные зависимости для образцов с разным содержанием СДС углерода. А контроль относительного содержания сопряженных двойных связей углерода в испытуемых образцах сополимеров проводился методом фотолюминесценции на спектрометре Joben Ivon - U1000 [5]. Спектрометр имел разрешение $0.2 \mathrm{~nm}$, в качестве источника излучения использовали ультрафиолетовый светодиод с максимумом спектра $365 \mathrm{~nm}$ и мощностью $1 \mathrm{~mW}$. Для пленок сополимера ПВХ-ПАЦ обнаружен один пик фотолюминесценции (рис. 2). По мере роста концентрации СДС углерода и связанных с ними сопряженной системы $\pi$-электронов происходит увеличение максимума фотолюминесценции. С увеличением длины цепочки сопряженных двойных связей углерода, которое зависит от числа СДС углерода, максимум фотолюминесценции смещается в длинноволновую область (т.е. в сополимере наблюдается батохромный эффект). Максимумы фотолюминесценции в зависимости от времени термообработки смещаются от 515 до $550 \mathrm{~nm}$. Данное смещение в длинноволновую область для полупроводниковых полимеров можно объяснить привлечением понятий молекулярных орбиталей: нижняя свободная молекулярная орбиталь (НСMO) и высшая занятая молекулярная орбиталь (ВЗМО). Отметим, что энергетический интервал между ВЗМО и НСМО в сопряженных полимерах можно условно уподобить ширине запрещенной зоны в неорганических полупроводниках. По мере увеличения времени термообработки растет число сопряженных двойных связей углерода в фрагментах ПАЦ и следовательно количество молекулярных орбиталей, а также связанных с ними $\pi$-электронов в сополимере ПВХ-ПАЦ. При этом энергетический интервал НСМО-ВЗМО уменьшается с ростом молекулярных орбиталей. Следовательно, энергия НСМО-ВЗМО уменьшается, а максимумы фотолюминесценции смещаются в длинноволновую область. Другими словами, наблюдается смещение максимумов фотолюминесценции в зависимости от числа сопряженных двойных связей углерода в цепи сопряжения. Так как длина цепей сопряжения в наших пленках составляет порядка 4-9 nm, можно говорить о квантово-размерном эффекте в сополимере ПВХ-ПАЦ.

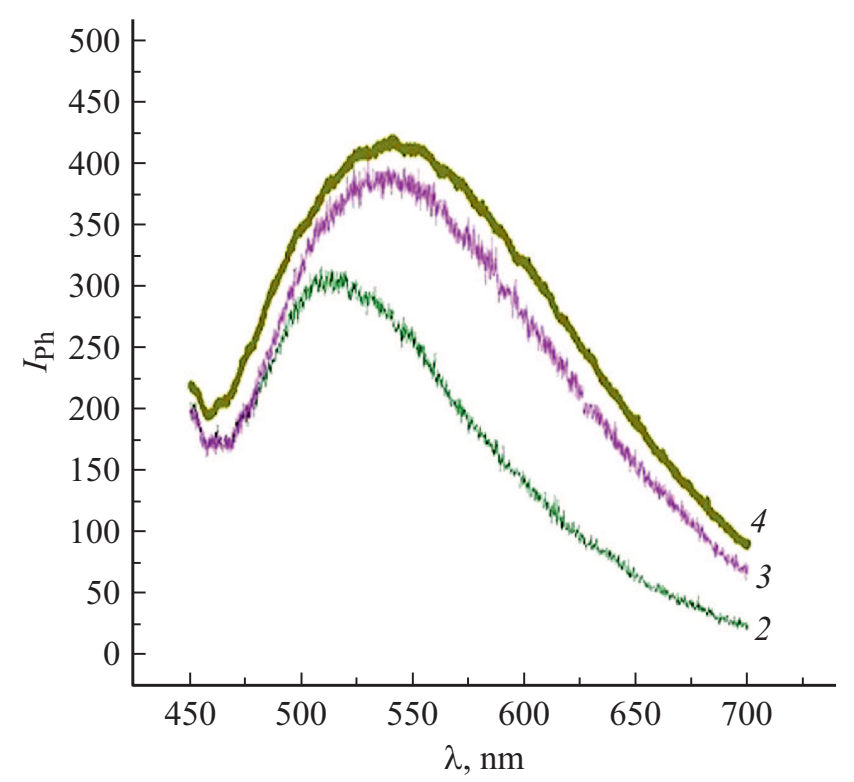

Рис. 2. Спектры фотолюминесценции: 2 - пленка сополимера ПВХ-ПАЦ, термообработка $240 \mathrm{~min} ; 3$ - пленка сополимера ПВХ-ПАЦ, термообработка $320 \mathrm{~min} ; 4$ - пленка сополимера ПВХ-ПАЦ, термообработка $420 \mathrm{~min}$. 


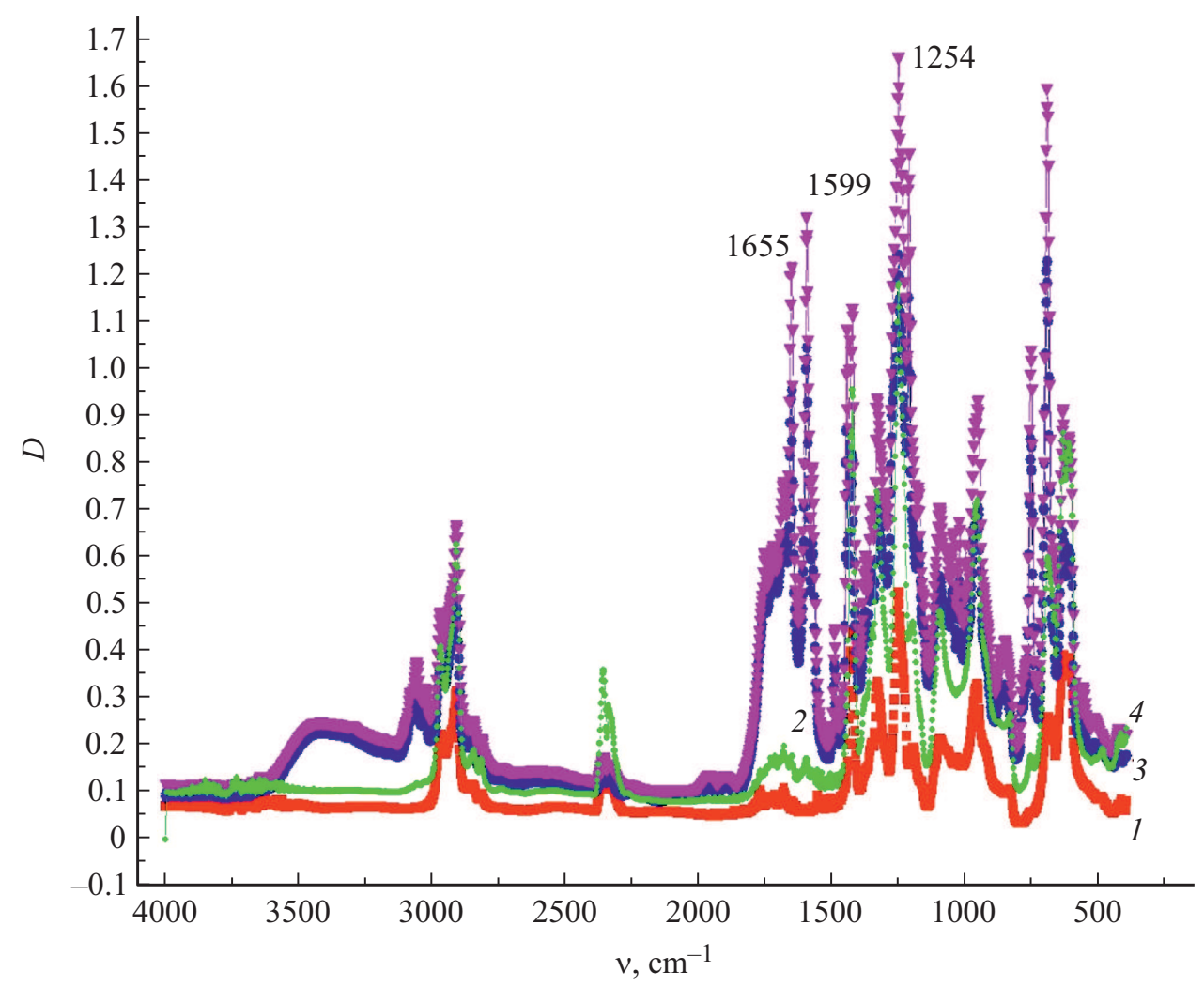

Рис. 3. Спектры FTIR: 1 - чистая пленка ПВХ, 2-4 - пленки сополимера ПВХ-ПАЦ.

Для подтверждения образования двойных связей углерода были сняты спектры FTIR (рис. 3).

Пики 1599 и $1655 \mathrm{~cm}^{-1}$ соответствуют валентным колебаниям двойных связей углерода $(\mathrm{C}=\mathrm{C})$. А пик $1254 \mathrm{~cm}^{-1}$ соответствует деформационным колебаниям С-Н. На рис. 3 видно, что пики 1599 и $1655 \mathrm{~cm}^{-1}$ растут по мере длительности времени термообработки, что непосредственно свидетельствует об увеличении двойных связей углерода $(\mathrm{C}=\mathrm{C})$. Пики $1254 \mathrm{~cm}^{-1}$ также увеличиваются с длительностью термообработки. Это говорит о росте количества $\mathrm{C}-\mathrm{H}$, которые дополнительно образуются в результате выделения молекул $\mathrm{HCl}$ и косвенно подтверждают образование $\mathrm{C}=\mathrm{C}$.

\section{Результаты и их обсуждение}

У исходной ПВХ пленки и всех сополимеров ПВХ-ПАЦ пленок были измерены объемные сопротивления при разных температурах нагрева. Для измерения использовали стандартный метод измерения сопротивления (тераомметр, измерительная ячейка, система нагрева), описанный в работе [7]. В качестве электродов использовали хорошо отполированные латунные контакты. Максимальная погрешность измерений сопротивлений пленок составляла порядка $10 \%$. На всех ПВХ пленках также были измерены вольт-амперные характеристики $(\mathrm{BAX})$, например, для образца $4 \mathrm{BAX}$ измерена при тем-

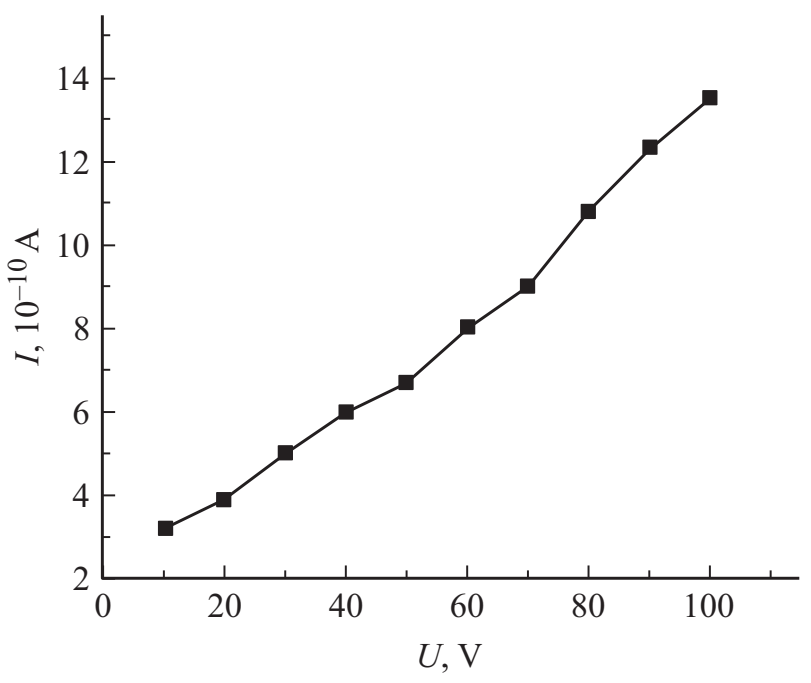

Рис. 4. ВАХ пленки 4 при температуре измерения $t=22^{\circ} \mathrm{C}$.

пературе $t=22^{\circ} \mathrm{C}$ (рис. 4) и при температуре $t=80^{\circ} \mathrm{C}$ (рис. 5).

Для измерения ВАХ использовали источник питания с регулируемым напряжением до $120 \mathrm{~V}$, наноамперметр и балластное сопротивление $10 \mathrm{M} \Omega$. Из рис. 4 и 5 видно, что в диапазонах от $10-110$ и $0.5-3 \mathrm{~V}$ сила тока от напряжения имеет практически линейный вид, поэтому контакты металл-полимер можно считать нейтральными. 


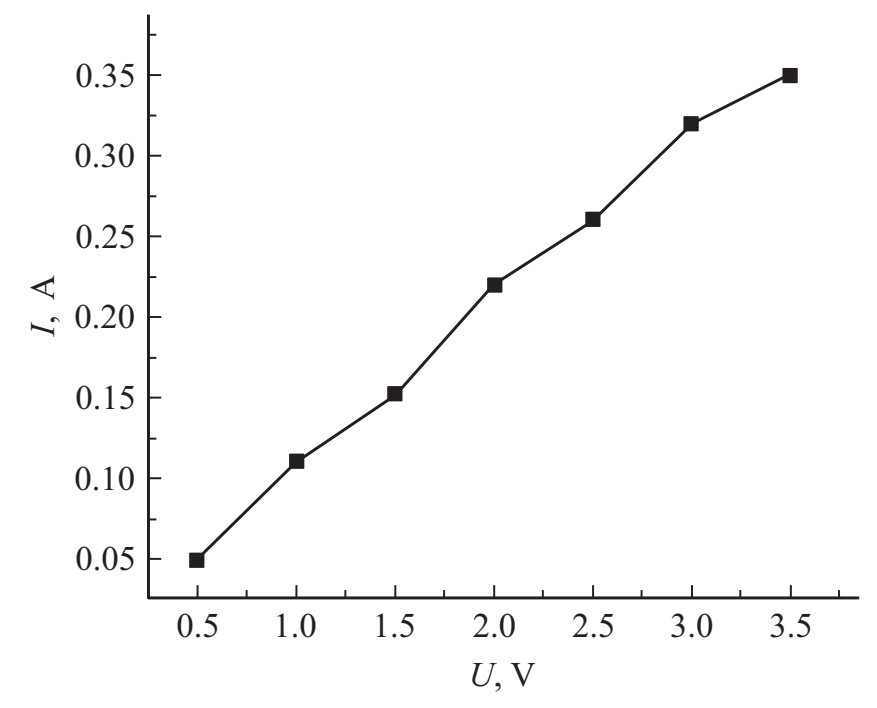

Рис. 5. ВАХ пленки 4 при температуре измерения $t=80^{\circ} \mathrm{C}$.

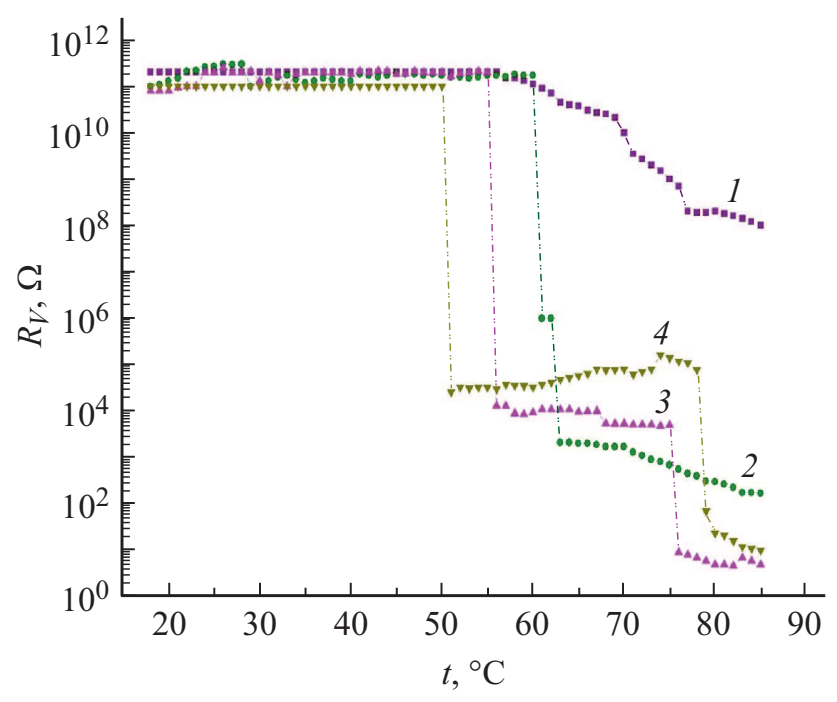

Рис. 6. Температурная зависимость объемного сопротивления $R_{V}(\Omega)$ образцов ПВХ и ПВХ-ПАЦ. 1 - исходный ПВХ, 2 - термообработка $240 \mathrm{~min}, 3$ - термообработка $320 \mathrm{~min}$, 4 - термообработка $420 \mathrm{~min}$.

Следовательно, инжекция электронов с контактов в образец ПВХ мала, и вклад в силу тока давали носители заряда самих пленок сополимера ПВХ-ПАЦ.

Для наших пленок гистерезис температурной зависимости сопротивления не наблюдался. При нагреве сополимеры ПВХ-ПАЦ переходили в полупроводящее состояние при температурах $t=70-80^{\circ} \mathrm{C}$ и при дальнейшем охлаждении оставались в этом же полупроводящем состояние $10^{3}-10^{4} \Omega \cdot \mathrm{cm}$ В таком состоянии сополимеры могли находиться достаточно долго (в течение нескольких дней).

В наших экспериментах зависимость проводимости образцов сополимеров не соответствует ни одному из известных перечисленных во введении типов темпера- турной зависимости материалов (рис. 6). Исключения составляют зависимости сопротивления для образцов $1-4$ в температурном диапазоне $60-80^{\circ} \mathrm{C}$ [8]. Данные зависимости можно объяснить переходами с одной цепи сопряжения на макромолекуле на другую цепь сопряжения другой макромолекулы [7]. Эти межмолекулярные переходы происходят за счет активационного прыжкового механизма.

Ситуация радикально изменяется уже при небольших количествах примесей фрагментов молекул ПАЦ. Так, для образца с термообработкой в течение $240 \mathrm{~min}$ (рис. 6) происходит скачок проводимости более чем на 5 порядков величины при температуре $t=60^{\circ} \mathrm{C}$, а затем сопротивление уменьшается до $10^{2} \Omega$ при температуpe $t=80^{\circ} \mathrm{C}$. Переключение проводимости происходит быстрее экспоненциального закона и может быть связано с резким перколяционным переходом из состояния диэлектрика в полупроводниковое состояние, когда при увеличении температуры энергия термически активированных электронов сопряженных $\pi$-связей становится достаточной для преодоления потенциальных изолирующих барьеров между фрагментами ПАЦ. Таким образом, наиболее вероятным представляется механизм переноса носителей заряда между проводящими включениями. В качестве проводников могут рассматриваться фрагменты ПАЦ (содержащего СДС), активированные примеси и термодефекты, возникающие в образцах ПВХ при нагреве [9]. Другими словами, происходят межмолекулярные переходы с одной цепи сопряжения на макромолекуле на другую цепь сопряжения другой макромолекулы ПВХ-ПАЦ, а также происходят переходы между проводящими фрагментами, содержащими активированные примеси и термодефекты [10]. Необходимо допустить, что цепь сопряжения является общей для двух или более макромолекул. В дальнейшем при изменении температуры образцов (при приближении к температуре стеклования $80^{\circ} \mathrm{C}$ ) происходит еще один скачок, носящий также ступенчатый характер, при котором значения $R v$ достигают значений порядка $10 \Omega$. Этот скачок можно связать с возможным переходом через температуру стеклования самого сополимера, когда кинетические сегменты макромолекул, содержащих полярные группы, приобретают значительно большую подвижность. Для пленки 2 энергия активации составила $E_{\mathrm{A}}=1.38 \mathrm{eV}$. Другой механизм возможного резкого увеличения проводимости может быть связан с локальным саморазогревом токового канала и соответствующим возможным увеличением носителей заряда, которые связаны с сопряженными двойными связями углерода. Точно такой же двухступенчатый характер изменения электропроводности имеют образцы со временем термообработки 320 и $420 \mathrm{~min}$. Однако здесь значения $R v$ в полупроводниковом состоянии на 2 порядка меньше $\left(R_{V} \approx 10^{4} \Omega\right.$.), чем для образца 2 . А полупроводниковое состояние сохраняется в более широком температурном диапазоне $50-75^{\circ} \mathrm{C}$. Следует отметить, что первый полупроводниковый скачок происходит при 
более низких температурах для образцов сополимеров с большим временем термообработки, т.е. при большем содержании в них СДС углерода (рис. 6), что на качественном уровне соответствует предложенной модели перколяции прыжковой проводимости. Таким образом, можно предположить, что проводимость измеренных термообработанных пленок описывается двумя механизмами: механизмом перколяционной прыжковой (в диапазоне температур $50-60^{\circ} \mathrm{C}$ ) и активационной прыжковой $\left(60-75^{\circ} \mathrm{C}\right)$ проводимостями.

Таким образом, были получены и исследованы оптические и электрофизические свойства сополимеров ПВХ-ПАЦ, обладающие управляющими полупроводниковыми и фотолюминесцентными свойствами. Данные полупроводниковые сополимеры можно использовать, например, в солнечных элементах в качестве заменителя широко распространенного сополимера полиэтилендиокситиофен-полистиролсульфонат (PEDOT-PSS).

\section{Заключение}

Анализируя полученные экспериментальные данные, приходим к следующим выводам:

1. Увеличение доли сопряженных двойных связей углерода (фрагментов ПАЦ) в макромолекулах исходного ПВХ, образующихся в результате увеличения времени термообработки, хорошо согласуется с данными по спектрам фотолюминесценции и инфракрасным спектрам этих же пленок.

2. Пленка исходного ПВХ при нагреве в интервале температур стеклования и размягчения $\left(t=15-85^{\circ} \mathrm{C}\right)$ уменьшает сопротивление на 2-3 порядка и попрежнему остается в классе диэлектриков.

3. Термообработанные пленки ПВХ, создающие сопряженные двойные связи углерода и связанные с ними $\pi$ электроны, способны переходить при увеличении температуры из состояния низкой проводимости в состояние высокой проводимости.

4. Переход для сополимеров ПВХ-ПАЦ из СНП в СВП при увеличении температуры носит двухступенчатый характер и проявляется более ярко при увеличении концентрации СДС в пленках сополимеров ПВХ-ПАЦ. При этом переход носит перколяционный (скачкообразный) характер.

5. На первой ступени перехода (со значениями $R_{v} \sim 10^{4}-10^{6} \Omega$ ) пленки сополимеров переходят из класса диэлектриков в полупроводящее состояние. Замечено, чем большее количество СДС углерода содержит пленка, тем при более низкой температуре происходит этот переход.

6. Максимумы фотолюминесценции сополимеров ПВХ-ПАЦ смещаются в диапазоне $515-550 \mathrm{~nm}$ в зависимости от числа сопряженных двойных связей углерода (размера цепи сопряжения), т.е. наблюдается квантоворазмерный эффект в сополимере.

\section{Конфликт интересов}

Авторы заявляют, что у них нет конфликта интересов

\section{Список литературы}

[1] Сажин Б.И. Электрические свойства полимеров. Л.: Химия, 1977.

[2] Блайт А., Блур Д. Электрические свойства полимеров. М.: Физматлит, 2008.

[3] Крыштоб В.И., Расмагин С.И. // ЖТФ. 2017. Т. 87. Вып. 11. С. 1687-1689.

[4] Крыштоб В.И., Власов Д.В., Миронов В.Ф., Апресян Л.А., Власова Т.В., Расмагин С.И., Кураташвили З.А., Соловский A.A. // Электротехника. 2015. № 8. С. 39-42.

[5] Власов Д.В., Крыштоб В.И., Власова Т.В., Апресян Л.А., Расмагин С.И. // Высокомолекулярные соединения. Серия A. 2015. T. 57. № 3. C. 242.

[6] Расмагин С.И., Крыштоб В.И. // Успехи современной науки. 2017. Т. 2. № 5. С. 54-57.

[7] Крыштоб В.И., Власов Д.В., Миронов В.Ф., Апресян Л.А., Власова Т.В., Расмагин С.И., Кураташвили З.А., Соловский А.А. // Электротехника. 2014. № 5. С. 60-63.

[8] Крыштоб В.И., Расмагин С.И., Власова Т.В. // Электротехника. 2018. № 6. С. 48-50.

[9] Rasmagin S.I., Krasovskii V.I., Kryshtob V.I., Feofanov I.N. Optical methods for controlling the degree of dehydrochlorination of polyvinyl chloride / Pulsed Lasers and Laser Applications - „AMPL-2017““ Abstracts of XIII International Conference. 2017. P. 64.

[10] Dong J., Fredericks P.M., George G.A. // Polymer Degradation and Stability. 1997. Vol. 58. P. 159. 